\title{
FORMAL SERVICE PROVISION AND THE CARE OF THE ELDERLY AT HOME IN IRELAND
}

\begin{abstract}
Social and demographic trends in Ireland pose the need to develop our system of care for the elderly at home. Currently informal care is the principal source of care for dependent elderly people with institutional care acting as the main alternative, particularly when levels of dependency are high or where informal caring relationships break down or are not possible. Although the past two decades have witnessed the growth of formal community care services for the elderly there is still considerable scope for extending and refining these services and, in particular, for making them more relevant to heavily burdened informal carers. Substitutionality appears to be the governing principle with formal and institutional services tending to step in only when the informal system breaks down. The achievement of greater complementarity between the formal and informal caring systems and the re-focusing of institutional services to provide support for the community care system as a whole are the suggested priorities.
\end{abstract}

Key Words: formal services, informal caregivers, institutional care, community care, Ireland

\section{DEMOGRAPHIC AND SOCIAL BACKGROUND}

In 1991, there were almost 395,000 people over the age of 65 in Ireland, constituting $11.2 \%$ of the population. Since the foundation of the Irish State in 1922 there has been a more or less uninterrupted growth in the number of elderly. Between 1926 and 1986 the population aged 65 or more rose by $41 \%$ from $271,680(9.1 \%)$ to $384,355(10.9 \%)$. There was a more rapid growth in the proportion of the population aged 75 to 84 years $(64 \%)$ and aged 85 or over (62\%). The highest proportions of elderly people are to be found in rural areas (Central Statistics Office 1989; 1991a).

These trends reflect the complex interaction of life expectancy, fertility and migration. Life expectancy has improved steadily to 71 years for males and 76.7 years for females at birth (1985-87) though this is low compared to the European Community (EC) as a whole (Central Statistics Office 1992). Fertility has until quite recently remained high: in 1986 there were 17.4 births per 1,000 population compared to 13.2 per thousand in England and Wales. Emigration, which took on mass proportions after the 1845-1848 famine, continues to be a significant and somewhat unpredictable factor.

The most notable demographic feature in Ireland until recently has been the high proportion of young people under 25 years, who made up $44 \%$ of the total population in 1991 (Central Statistics Office 1991a). In the medium term, therefore, there will be more rapid 'middle-aging' of the large, young cohorts before the most rapid rise in the 65 and over age group takes place, from 2011 onwards. Over the period to 2021 it is projected that the number of elderly will rise to 550,000 or $16 \%$ of the population. However, between 1986 and 2011 the 
number aged 85 and over will increase by $55 \%$ while the elderly as a whole will rise by only $14 \%$ (Central Statistics Office 1988). Projected increases in population are greatest in the urban areas. In the eastern region around the capital, Dublin, there will be a rise of up to $30 \%$ in the elderly by 2006 (National Council for the Aged 1985a: Appendix 2).

Social change in independent Ireland has included a dramatic fall in the rural population and a fall in the proportion of the labor force engaged in farming. Between 1926 and 1981 the proportion of the population living in towns of 1,500 or more increased from 32.3\% to 55.6\% (McKeown 1986). Between 1926 and 1988 the proportion of the labor force in agriculture fell from $53.4 \%$ to $15.3 \%$ with most of the change taking place since the late 1950s (Central Statistics Office 1991b).

The household structure of older people has changed significantly in recent decades as a result of smaller family size, earlier marriage, and greater social and geographic mobility. Between 1961 and 1986, the proportion of elderly persons living alone rose from $10.2 \%$ to $21.1 \%$ while the proportion of elderly living with spouse and no other co-residents increased from $9.5 \%$ to $20 \%$ in 1986 (National Council for the Aged 1985a).

\section{DEPENDENCY LEVELS}

There are no compehensive studies available comparing levels of dependency in random samples of the elderly across all types of household and institutional regime. What follows is evidence drawn from a few studies which together will give some impression of the level and distribution of dependency among the elderly.

In a national study of elderly people living outside institutional settings, Whelan and Vaughan (1982) found that $58.4 \%$ of men and $55.7 \%$ of women over 65 years had a long-standing illness, though only $7.2 \%$ of men and $6.7 \%$ of women complained of bad or very bad health at the time of the survey. Disability was measured in relation to various activities of daily living. The proportions reporting considerable difficulty or inability to carry out selected activities are given below:

$\begin{array}{llr}\text { Climb stairs } & \text { m } & 15.8 \% \\ & \text { f } & 22.5 \% \\ \text { Take bath } & \text { m } & 14.3 \% \\ & \text { f } & 23.7 \% \\ \text { Dress } & \text { m } & 4.1 \% \\ & \text { f } & 7.4 \% \\ \text { Read paper } & \text { m } & 3.8 \% \\ & \text { f } & 8.5 \%\end{array}$

These rates varied directly with age and were further associated with household type: the elderly living alone tended to have less difficulty than others.

O'Connor, Smyth, and Whelan (1988a) estimated that $17.5 \%$ of the national 
elderly population required some degree of care, either from a co-resident carer $(80 \%)$ or someone from another household providing significant amounts of care. Among these, 35\% required a lot of care, $35 \%$ required some care and the remainder required occasional care. In a follow-up study of recipients of care from a household member it was found that $71 \%$ were unable to get out of the house unassisted, or were more seriously immobile, and between one-third and one-half at least sometimes experienced symptoms associated with dementia (O'Connor, Ruddle, O'Gallagher, and Murphy 1988b: 68).

In a more ambitious study (Blackwell, O'Shea, Moane, and Murray 1992) a common Guttman scale was used to compare samples of elderly in four geriatric hospitals and a national representative sample receiving informal care in the community from a household member. There were five categories of dependency covering nine items of ADL ranging from no disability to inability to feed without help. There were $14.7 \%$ in the two highest categories (D or E) of dependency in the community sample compared to $55.4 \%$ in the hospitals sample. In these categories were those who could not, unaided, bathe, walk outdoors, walk indoors, get in or out of bed, sit or stand, use the toilet, wash hands and face and, for those in category E, feed themselves (see Table I)

TABLE I

Comparison of the distribution of elderly persons by category of dependency in hospitals and in the community

\begin{tabular}{lll}
\hline Category of dependency & \multicolumn{2}{l}{ Percentage of elderly } \\
\cline { 2 - 3 } & Hospitals & Community \\
\hline A & 21.8 & 45.5 \\
B & 7.0 & 19.7 \\
C & 13.1 & 13.0 \\
D & 16.1 & 9.1 \\
E & 39.3 & 5.6 \\
Non-scale & 2.7 & 7.1 \\
\hline
\end{tabular}

Source: Blackwell, O’Shea, Moane and Murray 1992: Table 11.1.

If we could generalize from the above geriatric hospital sample to all long-stay care, including private and voluntary nursing homes, health board welfare homes, and long-stay district hospitals, we could get a preliminary estimate of the overall numbers in categories $D$ and $E$. The writer has derived an estimate of 10,500 highly dependent elderly in institutional care on this basis, compared to an estimated 8,000 in receipt of informal care from a co-resident in a private household. In the absence of more comprehensive studies, this is the best indication that can be offered of the scale and location of high dependency, at the present time. Nevertheless, it shows that the role of informal care is crucial even in the context of the highest categories of dependency. 


\section{THE EXTENT OF INFORMAL CARE}

Studies in the mid 1980s first estimated the extent of informal care giving in Ireland (O'Connor et al. 1988a; O'Connor et al. 1988b). Some 66,300 elderly people $(17.5 \%)$ were estimated to be receiving significant levels of care from informal carers. Although these studies could not offer direct evidence on the changing capacity of society to provide informal care over time, they did show that higher proportions of the elderly received care if they lived in a farm household rather than in other household types. In rural areas $24.2 \%$ of the elderly were estimated to be receiving informal care, compared to $12.9 \%$ in urban areas. Also, among urban occupational groups, rates of informal care provision tended to be lower in white collar and managerial than in manual categories (O'Connor et al. 1988a: 31). Among professional and managerial classes the rate was $13.4 \%$ compared to $14.9 \%$ among other non-manual classes, $19.8 \%$ among skilled manual classes and $17.8 \%$ among other manual classes. From this cross-sectional evidence and what we know about urbanization and increases in white collar work it might be inferred that the capacity to offer informal care has declined to some extent as a result of urbanization. The crosssectional data might also point to improvements in functional status among the urban elderly though evidence is not yet available to support this interpretation. The extent of informal care in the mid 1980s was still considerable in all socioeconomic groups - despite the suggestion that it may be declining; for each elderly person in long-term institutional care there were more than three being cared for at home.

About 50,800 (or $80 \%$ of) carers identified were co-residents of the care recipient. The burden of care borne by these carers is considerably greater than that of carers living in separate households. Among co-resident carers in Ireland spouses account for $24 \%$, children for $46 \%$, and children-in-law for $19 \%$. Coresident female carers outnumber male carers by a factor of 4.5 to 1 . Female carers are more typically married $(75 \%)$ while male carers are usually single $(61 \%)$. Also, married carers may have the added responsibilities of childrearing.

The time devoted to caring is considerable, particularly when the carer is a coresident. Fifty per cent of these carers devote 4 to 7 hours a day to caring with $35 \%$ devoting more then 7 hours. Over half of carers are constantly 'on call'; over $70 \%$ feel confined some or all of the time, and $57 \%$ refer to being overwhelmed some or all of the time. One-fifth reported giving up a job in order to provide care (O'Connor et al. 1988b). More recent research confirms these findings. Blackwell et al. (1992) found an average of 47 hours per week given to caring among co-resident carers, and, as dependency increases, carers were found to spend an increasing proportion of time on personal care tasks in addition to instrumental caring tasks. Again, there was evidence of psychological strain with over one-third experiencing a variety of types of strain or stress.

Labor force participation rates for women in Ireland are low by international standards, particularly in the case of married women. The rate for married 
women, however, has increased from $7.5 \%$ in 1971 to $23 \%$ in 1989 , a factor that might be expected to restrict the availability of informal care in the future (Blackwell et al. 1992: 7). Nevertheless, opportunity costs of caring are considerable, even allowing for the effects of labor market slackness and traditionally low labor force participation rates of married women. Loss of leisure time and time devoted to home duties have led some researchers to the view that care in the community is not a very cheap option (O'Shea and Corcoran 1989). In the past, informal care may have been particularly undervalued due to the low labor force participation rate among women, particularly married women, as noted above, and traditional assumptions about women's role in society. Blackwell et al. (1992) estimated the opportunity cost of an average co-resident carer's time at IR£43.30 (\$70) per week. They noted that using a public expenditure valuation, i.e., the hourly rate attributed to home helps employed by health boards, increased the average cost to IR£111.80 $(\$ 180)$. Until the opportunity cost rises, for example in response to greater scarcity of carers, there may well be a reluctance to provide improvements in subsidies to informal carers. Currently a Carers Allowance of up to $£ 55$ per week is paid to means-tested carers providing full time care. However, less than $10 \%$ of co-resident carers receive this payment and less than half of these receive the full allowance (Dail Eireann March 1992: 825-826).

\section{COMMUNITY CARE POLICY}

Government policy on the care of the elderly, as well as policy on the care of the mentally ill or handicapped, has been to emphasize the benefits, both personal and financial, of community care. In a key report from the 1960s, the Interdepartmental Committee on the Care of the Aged stated that "it is better and probably much cheaper to help the aged to live in the community than to provide for them in hospitals and other institutions" (Department of Health 1968: 13). At the time of this report policy makers were conscious of the emphasis that had previously been placed on the provision of custodial style institutional care, particularly in county homes - large, very old institutions which had their origins in the 19th Century Poor Law. Although many had been closed in the previous decades and the better ones improved, they were too often provided as a substitute for inadequate housing, low income and a paucity of services for the elderly living at home.

The Interdepartmental Committee put forward a detailed list of progressive recommendations on income maintenance, housing and community care. It was forward-looking too in suggesting that the concept of 'County Homes' be abandoned and replaced by a system of hospital and institutional care emphasizing assessment and rehabilitation and assignment of patients to the most appropriate regime as determined by their needs. Following publication of its report there was considerable expansion of existing services and inauguration of new services particularly in the community. The voluntary sector was to play a significant part in providing personal social services and the statutory authorities 
were encouraged to provide more funding for these services. Public housing programs were significantly better funded in the late 1960s, 1970s and early 1980s. This expansion benefited many elderly people who tended to live in the oldest and least adequately equipped accommodations. Pensions provided by the state were improved significantly during this period as a whole, and a number of special allowances were introduced such as free travel for all persons aged 66 or over. Free phone rental, free TV licenses and free units of electricity were introduced for many pensioners while pension supplements were given to those living alone or over 80 years of age.

These factors - key elements of a welfare state - have contributed substantially to improving the social and economic welfare of the elderly by reducing the risk of poverty, bad housing, and other ills. Alongside these developments has been the expansion of the health services budget. This expansion has not been altogether linear, however, and has been affected by economic developments nationally and world-wide. During the 1980 s especially, cutbacks in public spending brought about considerable pressure on health service provision, resulting in reductions in acute hospital beds and cuts in community care services. In 1988, when a new policy document entitled The Years Ahead - A Policy for the Elderly was published, the scope for new services was to be subject in large measure to ability to re-deploy existing resources (Department of Health 1988). The impact of these trends will be referred to below in discussing institutional and community services. A more recent and important development was the signing by unions, employers, and government of a Programme for Economic and Social Progress (Department of an Taoiseach 1991) which committed the government to increasing community care spending over 7 years to cover current and capital items. The full implementation of this program would make it easier to realize the aspirations and targets set out in The Years Ahead report.

\section{INSTITUTIONAL CARE PROVISION}

Meaningful trends in institutional provision are difficult to establish because of the complex and changing patient mix and care processes which have characterized various hospitals and homes throughout recent decades. The most general index of institutionalization we have is provided by the population census. This includes all those in short- and long-term accommodation and in medical and non-medical settings. Between 1966 and 1986 the proportion of elderly in this category increased from $8.15 \%$ to $8.55 \%$ (Central Statistics Office $1969 ; 1989$ ).

The allocation of this portion of the elderly between various institutional settings is more difficult to estimate. In 1988, it was estimated that there were about 19,000 beds providing long-term care for the elderly in the public, voluntary, and private sectors (O'Shea, Donnison, and Larragy 1991). Although exactly comparable figures are not available for the 1960s, the Interdepartmental Committee on the Care of the Aged suggested that in 1966 there were about 
15,000 beds for elderly people in a range of institutions providing long-term care (Department of Health 1968). Both of these figures exclude psychiatric hospitals but cover geriatric hospitals or homes, certain district hospital beds, and private or voluntary nursing homes. In overall terms this suggests an increase over this period from $4.5 \%$ to $4.9 \%$ in the proportion of elderly people in institutions providing long-term care. In sectoral terms the most significant change between 1966 and the present has been the growth in private (including voluntary) nursing home provision of over $160 \%$ from 3,470 beds in 1966 to 9,060 in 1988. Within the statutory long-stay sector there were more subtle changes: a reduction in the number of geriatric hospital beds and better targeting of these towards the ill elderly; provision of up to 1,500 new beds in welfare homes, and re-deployment of many local district hospital beds from maternity, medical, and other purposes to geriatric care.

Among these changes the one least anticipated by policy makers in the 1960 s was the increase in private nursing home provision. Growth in this sector was very likely accelerated in the 1980 s as a result of public expenditure cutbacks. These cutbacks resulted in a decrease in the number of acute hospital beds staffed by consultants from 16,150 in 1981 to 12,100 in 1988 (Dail Eireann, October 1991: 338). Some of these cuts were aimed at improving effectiveness as well as making savings, and it should be noted that between 1976 and 1985 public spending on non-capital health programs increased by $45 \%$ in real terms with a slight increase in the share allotted to acute hospital budgets (O'Connor 1987). Reduced psychiatric hospital bed numbers may also have contributed to the incease in private nursing home provision. Between 1981 and 1991 total inpatients here fell from 13,984 to 8,207 . Over the same period the number of elderly patients per 100,000 fell from 1,229 to 745 for those aged 65 to 74 and from 1,609 to 1,049 for those aged 75 and over (Moran and Walsh 1991: 16).

Policy concerns in relation to institutional care for the elderly in the 1980 s have also focused on the need to transform the type of service offered. From small beginnings there has been a systematic increase in the number of specialists in geriatric medicine in acute hospitals. More emphasis is being placed on assessment prior to admission to long-stay beds in geriatric hospitals and welfare homes. Alternative welfare accommodation, such as sheltered housing and boarding-out, are now favored over the continued building of welfare homes. Several bodies have recommended that geriatric hospitals adopt a more flexible role in collaboration with community care providers by, for example, providing short-term respite or intermittent care and rehabilitation in addition to extended care. The concept of a community hospital has been put forward to embody this approach (National Council for the Aged 1985b; Department of Health 1988). Realization of this concept has been uneven, however, and in the past few years much more attention has been focused on providing new legislation for the private nursing home sector and agreeing on the level of state subvention to be paid towards such care. The Health (Nursing Homes) Act, passed in 1990, has yet to be implemented.

Overall, the trend in institutional care in recent decades has been upwards in 
absolute and relative terms. There has also been, in the period 1981 to 1986 , some increase in the proportion of very elderly in institutions and a fall in the proportion of younger elderly - suggesting at least a degree of targeting of such care. In the last decade, however, there has also been a reduction in the use of acute and statutory long-stay beds. This has not been balanced by increased community care services, although these have been increasing - but primarily by rising demand for private nursing home care.

\section{THE EXTENT OF FORMAL HOME CARE SERVICES}

Prior to the 1960 s, institutional care was the principal focus of public policy relating to the elderly. The Interdepartmental Committee on the Care of the Aged (Department of Health 1968) acknowledged that key services such as domiciliary nursing, home help, meals, occupational therapy, physiotherapy, chiropody, social work and speech therapy were very unevenly available and unavailable in several areas. Unlike the provision of general medical services these services were not mandatory at that time. The Committee recommended the expansion of all these services and the development of other services such as boarding out, day centers, and, on a pilot basis, day hospitals in more densely populated areas. The 1970 Health Act provided for improved funding of many of these services and set up 8 regional health boards to replace the more numerous local health authorities. Each of these health boards was to have a community care program with budget lines covering services to be provided either directly by health board employees or by other, e.g., voluntary, agencies. These services are discussed below.

General medical services provided by private practitioners (GPs), as noted above, are widely available. Since 1970 persons below a certain income may use a GP of their choice, whose services will be provided free. They also receive free pharmaceuticals on prescription by a GP. Over $70 \%$ of the elderly are covered under this program. Until 1990, GPs were paid on a fee-per-item basis, but this has been replaced by a capitation arrangement. It is not yet known how this has affected services for the elderly although there are additional loadings for GPs with higher proportions of elderly patients.

Public health nurses, physiotherapists, occupational therapists, and speech therapists are employed by health boards. The voluntary sector plays a major role in providing domiciliary services such as home help, meals-on-wheels, laundry, and day care services but depends on the health boards for much of the funding for these services.

In the case of public health nurses (PHNs) a working group (Department of Health 1975) recommended a target ratio of 1 per 2,616 general population. It noted that almost $70 \%$ of home visits by PHNs and $39 \%$ of their time related to the elderly. Some $50 \%$ of the elderly on PHN lists were patients for more than one year, but $90 \%$ of patients were visited less than weekly. By 1988, although the number of PHNs had improved, the ratio stood at 1 per 3,065 - well short of the ratio suggested in 1975 and very low by comparison with the U.K.'s 
recommended norm of 1 per 1,722 (Department of Health 1988). The provision of intensive nursing, liaison with general practitioners, and even adequately long visits suffer from this lack of personnel. Since the adoption of a new policy document, The Years Ahead - A Policy for the Elderly (Department of Health 1988), there has been renewed emphasis on the need to develop the PHN service. The number of PHNs has recently been expanded despite continued public spending restraint in other sectors of the health service, and over the past few years PHNs have been involved in service innovation. For example, as recommended in The Years Ahead, PHNs were to have a leading role in teamwork between providers at the local level. In the Eastern Health Board, which includes 1.2 million people in its catchment area, district teams have since been established to provide intensive interdisciplinary support for selected elderly people, who may be referred to them by hospitals or GPs for short-term high support at home. Patients include those who are discharged earlier from hospital beds than was previously the case. They are given intensive nursing care, therapy, and home care support for a few months before being referred to the normal community care services. This program is being evaluated. Panels of part-time general nurses at the local level were also recommended in The Years Ahead to provide intensive home nursing care in a more cost effective manner than PHNs could possibly do. It is believed that there are considerable numbers of qualified nurses who left the labor force following marriage who might be available on a part-time basis for this.

Several professional health services for the elderly are in need of expansion. Occupational therapy has been improved and is increasingly a home- or community-based service. At the end of 1990 , there were 190 full-time equivalent OTs employed by health boards (Dail Eireann, March 1992: 1,642). Although there are some 434 physiotherapists employed by health boards, domiciliary physiotherapy is as yet underdeveloped. The Years Ahead acknowledged that a physiotherapy service was virtually non-existent for the elderly living at home. Obviously this in turn hampers the development of teamwork at the local level. As speech therapy is not commonly available at home as a statutory service, The Years Ahead recommended that a domiciliary speech therapy service be developed for stroke victims. Community social workers employed by health boards are so heavily in demand in meeting the needs of children at risk that they play only a marginal role in the care of the elderly at home. There are social workers in the main hospitals, but they cannot meet the needs of elderly people in the community following discharge.

Just as important as the provision of health services is the provision of support services such as home help and meals, either at home or nearby in day care centers. Since 1970, legislation has empowered, though not required, statutory health boards to directly provide or fund voluntary bodies who will deliver a home help service. From small beginnings the service has gradually grown to the extent that, in 1990 , approximately $11,400(2.9 \%)$ elderly people were receiving a home help service. One of the main purposes of the service is to avoid unnecessary residential service provision. The service tends to be very 
uneven with regional disparities in level and frequency of provision, charges, and rates of pay to largely part-time home helps, and there is little objective evaluation of the standard of provision. Implicitly the service is aimed at elderly people living alone while it tends to be least available to those elderly who reside with a carer. About half of the home help service is under the management of locally based voluntary organizations while the statutory health boards directly manage the remainder. In 1988 The Years Ahead recommended that provision of this service should be expanded substantially and given a stronger legal mandate. The report also stated that home help services should be made more comprehensive so as to include assistance with all tasks of daily living, an evening and weekend relief service for carers in the home, and an emergency service at a day's notice in special circumstances, e.g., following hospital discharge or in the event of illness or sudden unavailability of a carer (Department of Health 1988: 97).

Meals-on-wheels delivered to elderly people at home or meals provided in day centers constitute another significant part of home care. Here the voluntary sector is the main provider though funding comes from statutory sources as well as from charges to clients. Approximately $2.8 \%$ of elderly people now receive a meals service, compared to $1.9 \%$ in 1977.

As with home help, policy makers are concerned about the best way to develop meals services. While health boards are empowered to fund these services, the funding has always been discretionary. During the period from 1982 to 1988 real public expenditure on these services actually fell - with obvious consequences for the level of provision. The heavy reliance on part-time and low waged labor - effectively stipended volunteers in many instances might be threatened by a move towards more formal contractual relationships between statutory and voluntary providers and between providing agencies and clients. And yet it is accepted that such support services are often the key to maintaining independence and to avoiding - or at least postponing - admission to residential care.

One of the issues that has emerged in this context is the absence of an adequate framework for voluntary-statutory partnership. The government has recently initiated a working party which will draft a White Paper and Charter on voluntary organizations in the near future. The National Council for the Elderly in a new research study recommends that services such as home help, meals, and day care services be differentiated from the many other types of voluntary activity (such as visitation and social contact) for the purpose of funding and planning by designating them as "core" services underpinned by legislation. On this basis the problem of improving quality, level and accessibility may be more adequately addressed. Currently these services tend to be funded on the same discretionary basis as many other less vital, albeit useful and important, voluntary social services (Mulvihill 1993).

In general, the past 25 years have witnessed an expansion, from small beginnings, of several community care services. There is still considerable room for growth of these services. Compared with 5\% in institutional care and $17.5 \%$ 
receiving informal care, the $2.8 \%$ to $2.9 \%$ of older people receiving home help or meals services seems low. Moreover, the coordination of such home care services is a question that has not yet been adequately resolved. There is also a considerable degree of unevenness in the way services are put in place, regulated, and funded. This lack of coordination and unevenness can only reinforce the difficulties involved in relating these services to the needs of the informal caring network.

\section{COMPLEMENTARITY OF FORMAL AND INFORMAL HOME CARE}

In addition to expanding formal home and community care services, it is necessary to address the question of what relationship exists between these services and the care provided informally by relatives of the dependent elderly. A study of co-resident carers of the dependent elderly (O'Connor et al. 1988b: 129) revealed that while some degree of pracitcal and emotional support does come to carers from informal sources, it tends to be occasional and confined to instrumental tasks. The heavy, personal care tasks associated with highly dependent elderly are mainly left to the principal carer.

Evidence of formal support for carers was also gathered in this study. Within the 6 months prior to the interview, $80 \%$ of informal care recipients utilized the services of a GP and $89 \%$ of the carers affected reported that such visits were helpful in relieving the caregiving burden. Within the previous 6 months $47 \%$ of care recipients saw the PHN though $63 \%$ of these visits were less than once a fortnight. While the majority of carers affected expressed their approval of this service for easing the burden of care, it is notable that $29 \%$ felt that PHN visits were not frequent enough and $21 \%$ that they were not long enough. Home help and meals services were received, respectively, by only $1.5 \%$ and $0.5 \%$ of informal care recipients with co-residing carers. This is a startling finding since the equivalent rate for the elderly population as a whole is, in each case, close to $3 \%$. Visits from a social worker or occupational therapist were received by only one case each. Again, this is not very reassuring. Occupational therapists could meet the need to reduce the physical burden on carers by providing advice on making the home a more prosthetic environment which fosters independence for the care recipient. Social workers, by engaging in family work, advocacy and counselling, could help to address stressful relationships and gain access to other services. Overall, $80 \%$ of informal care recipients received fewer than 4 of 12 potential services (home help, meals, GP, PHN, chiropodist, social worker, OT, official, clergy, support group, private nurse, private household help) while a further $11 \%$ received none at all.

Carers were more inclined to apply for and less likely to be refused certain services, particularly mobility and personal care aids and nursing help. However, of the $5 \%$ who applied for home help $70 \%$ were refused it. While there is some evidence of service complementarity in the case of the GP and the PHN, there is considerable scope for expanded support - particularly home nursing - for carers. Moreover, services such as home help and meals, evidently, 
are substitutional services made available only in the absence of a carer. These services originated at a time when social expectations regarding informal care provision within households were significantly higher, and the formal services were accordingly targeted at the elderly living alone. Now there is more acceptance of the idea of offering these types of services to ease the burden on carers. In addition, as noted previously, the diversification of these services to provide sitting and respite care at home could contribute significantly to the well-being of carers. However, as in other countries, the prevailing view continues to define the role of formal service providers largely in terms of stepping in when the informal caring relationship is at the point of breakdown. This can only result in a failure to anticipate difficulties by providing preventive support for carers. In order to overcome this problem professionals need to develop a more sophisticated understanding of the complex status of carers - as both co-providers and co-clients - and to develop new ways of involving them in the planning and delivery of support.

\section{CONCLUSION}

There are few extremes in Ireland in demographic, social, or policy terms, when compared with a range of developed and developing countries. Ireland is experiencing a variety of problems in relation to the development of home care services for the elderly which are fairly typical of other countries. Systems of care are provided through the informal, statutory, voluntary, and private sectors. However, institutional, formal and informal community caring systems have developed somewhat independently of one another, and this is a problem which requires attention. An expansion of formal community care resources with a greater emphasis on complementing the informal system is one key priority. A re-definition of the role and function of acute and long-stay institutions with a more supportive role in relation to community care is another. The realization of these goals is a complex and expensive task with implications for the design and operation of integrated care systems and new types of funding mechanisms. The careful evaluation of existing services and organizational arrangements and research on the future financing of continuing care will be essential to the achievement of an effective system of home care for the elderly.

\section{ACKNOWLEDGEMENTS}

I would like to thank the National Council for the Elderly for time and support in preparing an earlier draft as a contribution to the 13th Annual Symposium on Home Health Care and the Elderly at Case Western Reserve Univesity, and Céline Kinsella and Carol Waters for their patient and expert typing of the manuscript. Responsibility for the views and accuracy of the data presented here rests solely with the author. 


\section{REFERENCES}

Blackwell, J., E. O'Shea, G. Moane and P. Murray 1992 Care Provision and Cost Measurement; Dependent Elderly People at Home and in Geriatric Hospitals. Dublin: Economic and Social Research Institute.

Central Statistics Office 1969 Census of Population 1966 Volume 6: Age. Dublin: Stationary Office.

Central Statistics Office 1988 Population and Labour Force Projections 1986-2021. Dublin: Stationary Office.

Central Statistics Office 1989 Census 86 Volume 2: Ages and Marital Status. Dublin: Stationary Office.

Central Statistics Office 1991a Census of Population of Ireland 1991 Preliminary Report; Age Groups. Dublin: Stationary Office.

Central Statistics Office 1991b The Trend of Employment and Unemployment 1986-1988. Dublin: Stationary Office.

Central Statistics Office 1992 Irish Life Tables 1985-1987. Dublin: Stationary Office.

Dail Eireann October 1991 Parliamentary Debates: Official Report. Dublin: Stationary Office.

Dail Eireann March 1992 Parliamentary Debates: Official Report. Dublin: Stationary Office.

Department of an Taoiseach 1991 Programme for Economic and Social Progress. Dublin: Stationary Office.

Department of Health 1968 The Care of the Aged: Report of an Inter-Departmental Committee. Dublin: Stationary Office.

Department of Health 1975 Survey of Workload of Public Health Nurses: Report of a Working Group Appointed by Minister for Health. Dublin: Stationary Office.

Department of Health 1988 The Years Ahead: A Policy for the Elderly. Dublin: Stationary Office.

McKeown, K. 1986 Urbanisation in the Republic of Ireland: A Conflict Approach. In Ireland - A Sociological Profile. P. Clancy, S. Drudy, K. Lynch, and L. O'Dowd, eds. Pp. 362-379. Dublin: Institute of Public Administration.

Moran, R. and D. Walsh 1991 The Irish Psychiatric Hospitals and Units Census 1991. Dublin: The Health Research Board.

Mulvihill, R. 1993 Voluntary-Statutory Partnership in Community Care of the Elderly. Dublin: National Council for the Elderly.

National Council for the Aged 1985a Housing of the Elderly in Ireland. Dublin: National Council for the Aged.

National Council for the Aged 1985b Institutional Care of the Elderly in Ireland. Dublin: National Council for the Aged.

O'Connor, J., E. Smyth and B. Whelan 1988a Caring for the Elderly Part 1: A Study of Carers in the Home and in the Community. Dublin: National Council for the Aged.

O'Connor, J., H. Ruddle with M. O'Gallagher and E. Murphy 1988b Caring for the Elderly Part 2, The Caring Process: A Study of Carers in the Home, Dublin: National Council for the Aged.

O'Connor, S. 1987 Community Care Services: An Overview. Dublin: National Economic and Social Council.

O'Shea, E. and R. Corcoran 1989 The Placement of Elderly Persons: A Logit Estimation and Cost Analysis. Economic and Social Review 20: 219-241.

O'Shea, E., D. Donnison and J. Larragy 1991 The Role and Future Development of Nursing Homes in Ireland. Dublin: National Council for the Elderly.

Whelan, and Vaughan 1982 The Economic and Social Circumstances of the Elderly in Ireland. Dublin: Economic and Social Research Institute. 
National Council for the Elderly

Corrigan House

Fenian Street

Dublin 2

Ireland 